\title{
3D RECORDING AND MODELLING OF MINING HERITAGE: THE MONSERRAT MINE, SIERRA MINERA OF CARTAGENA-LA UNIÓN, SOUTHEAST OF SPAIN
}

\author{
J. García-León ${ }^{\text {a }}$, A. García Martín ${ }^{\text {b }}$, M. Torres Picazo ${ }^{\text {b }}$, J. Fernández ${ }^{\text {a }}$ \\ ${ }^{a}$ Dept. of Architecture and Building Technology, Technical University of Cartagena, Spain - josefina.leon@upct.es, \\ jaimefv91@gmail.com \\ ${ }^{\mathrm{b}}$ Dept. of Mining, Geological and Cartographic Engineering, Technical University of Cartagena, Spain - (antonio.gmartin, \\ manuel.torres)@upct.es
}

Commission II

KEY WORDS: Industrial Heritage, documentation, laser-scanning, modelling, mining premises, risk of collapse

\begin{abstract}
:
Mining heritage is essential to understand the history, landscape and cultural manifestations linked to mining industry. The Mountain Range of Cartagena-La Unión is one of the most relevant old Mediterranean mining areas, with mining sites that were already exploited before the Carthaginian domination. It was declared a Site of Cultural Interest in 2009. Our aim is to document and to enhance its premises, which are currently in a bad state of preservation and have been plundered. The methodology that we suggest combines various techniques, such as laser scanning, LIDAR and digital photogrammetry, in order to obtain the best results based on the characteristics of the objects to be inventoried. For this study, we have chosen an area in which a digital model has been created by means of terrestrial laser scanning and airborne LIDAR, then we have textured it with the images taken. With this model, it is possible to measure the deterioration and displacement suffered by its elements, in particular, the chimney and the boiler room.
\end{abstract}

\section{INTRODUCTION}

The industrial heritage, in accordance with the International Committee for the Conservation of the Industrial Heritage, is made up of the remains of old machinery and industrial buildings that have a certain value, whether historical, technological, cultural, architectural or scientific. This is one of the areas that UNESCO has selected as emblematic in order to understand the past linked to industrial revolutions, which took place from the $18^{\text {th }}$ to $20^{\text {th }}$ Centuries and left their mark on the landscape and on the culture of the places affected by them. Thus, the documentation of the old remains becomes a metaphor allowing to understand the past from today's perspective (Marcos, Martínez, Delgado and Finat, 2016).

The mining heritage represents an essential part of the industrial heritage. It is made up of some remains -not only materials- of the activities that have contributed to shape the collective memory of many mining regions, and it is of great interest to scientists from a range of disciplines, such as history, economics, geography, sociology, architecture, etc. (Cañizares, 2011). The mining heritage includes machinery, premises, buildings, transport routes and even gaps resulting from mining operations (whether underground or opencast) and geology linked to them (in this case, we could talk about geologicalmining heritage). Moreover, documents generated by the mining activity and the cultural and artistic manifestations linked to the mining industry form -among others- an intrinsic part of the mining heritage.

Sierra Minera, the mountain range of Cartagena-La Unión (located in the southeast of Spain), is one of the most relevant historical mining areas in Spain, although the mining activity has disappeared since the late $20^{\text {th }}$ century. Its mining sites were exploited before the Carthaginian and Roman domination, with periods of great splendour followed by periods of decline. Many remains of the mining activity still survive in this mountain range. As certified by UNESCO (Mining Historical Heritage), most of them correspond to one of the periods of greatest activity, the period from the last third of the $19^{\text {th }}$ Century to the beginning of the $20^{\text {th }}$ Century. The mining splendour of that time is reflected in the modernist houses that were built for many mine owners in the cities of Cartagena and La Unión; however, hardness and risks inherent in the work carried out by miners have also left their mark on the popular culture of the area. There is even a type of flamenco singing known as "minera", which is particular to this mountain range and arose due to the migration of workers from Andalusia.

Sierra Minera was declared a Site of Cultural Interest in 2009, under the category of Historical Site. This declaration recognizes the value of the mining heritage of this mountain range, given that it contributes to the representation of the cultural identity of the region. However and so far, this declaration has not given rise to any effective improvement in heritage protection, which is exposed to deterioration and plundering, and an important part of the said heritage is in ruins or has disappeared and it may not be recovered. This situation is not exclusive to Sierra Minera, but it also applies to a significant part of the industrial heritage of the country (Cañizares, 2011).

This paper has been focused on a part of the premises belonging to the mine of Our Lady of Monserrat (hereinafter, Monserrat), located at the emblematic hill known as "Cabezo Rajao", which was an underground mining site exploited since the middle of 
the $19^{\text {th }}$ Century until the middle of the $20^{\text {th }}$ Century: the chimney and the boiler room. Our aim has been to document these premises due to their deterioration and the risk of collapse of the chimney, as well as to test and to refine the used methodology, for the purposes of considering its application to the huge quantity of old mining premises located in this mountain range. Thus, we would like to contribute to the documentation and enhancement of this heritage.

\section{THE STUDY CASE}

The mining activity in the mountain range of Cartagena-La Unión started around the $5^{\text {th }}$ Century BC. In the $3^{\text {rd }}$ Century BC, Carthaginians extracted from this mine a part of the iron and silver necessary to support their wars against Rome. Mining at Cabezo Rajao dates back, at least, to the Romans, who exploited the mining sites in this mountain range from the $2^{\text {nd }}$ Century BC to the $3^{\text {rd }}$ Century AD. During the Arab domination and in subsequent centuries, mines were also exploited, but in a quite limited way. It was in the $19^{\text {th }}$ Century, when mining started to recover, due to the industrialization and technological advances. With all its highs and lows, mining was a priority activity in Sierra Minera until it disappeared in the early $90 \mathrm{~s}$. Lead, silver, iron, zinc and sulphur minerals were extracted, as well as tin, copper, manganese and alum.

Cabezo Rajao is a hill located between Cartagena and La Unión. It is a sub-volcanic structure made up of rocks belonging to the family of andesites-dacites and it was formed by differential erosion. "Cabezo" is a local term meaning "hill" and "rajao" (or "rajado") means "cracked": this name makes reference to a great surface seam, which crossed it and was opencast mined by the Romans, which left a great crack that is partially filled. From the $19^{\text {th }}$ to the $20^{\text {th }}$ Centuries, several mining sites were exploited at this hill, all of them underground. Figure 1 shows a view of Cabezo Rajao in 1910, with mining sites under exploitation.

The Monserrat mine was one of the most productive mines in this hill. Figure 2 shows the original map of the claim, which dates from 1852. Figure 3 shows a sketch of the mine premises. Like a significant part of the archaeological-industrial heritage of this area, they are in a bad state of preservation (Banos and Baños, 2013). The head frame (1) still survives. It is made of metal, although other mines had wooden or masonry head frames. Mineral was extracted through the mine shaft, by means of cages activated by the steam machine located in a nearby building (2). The boiler room (3) housed three boilers used to generate the steam necessary to activate the extraction shaft machinery. Timber harvested from this mountain range was used as fuel, given that coal had to be imported from England and it was excessively expensive.

Fumes generated from the combustion of timber in the three boilers circulated through three tubes, which subsequently joined a common tube that climbed the slope located behind the boiler room until reaching the base of the chimney (4). The tube is a trench, which may be still observed and was once covered. Given that the chimney is located on an unstable ground, a great retaining wall was built in order to support it. Chimneys were built to extract fumes generated by the steam machines or by the foundries. Chimneys corresponding to the first type were always close to a head frame. They were built with bricks joined together with mortar, a mix of sand, lime and water. Sixteen of these chimneys are still present in Sierra Minera. The chimney that is relevant to us is quite deteriorated and has numerous cracks and an inclination that is increased with height.

The boiler room is in ruins; it has lost the whole roof and there are gaps in its walls. There are not any remains of boilers inside. At its back, three arches may be observed, through which the tubes connected to the chimney came out. Premises also include a washing plant (5) built in 1950 approximately, when gravimetric methods - mainly used until the $40 \mathrm{~s}-$ were replaced with differential flotation. The washing plant is also quite affected by plundering, although some of its elements still remain.

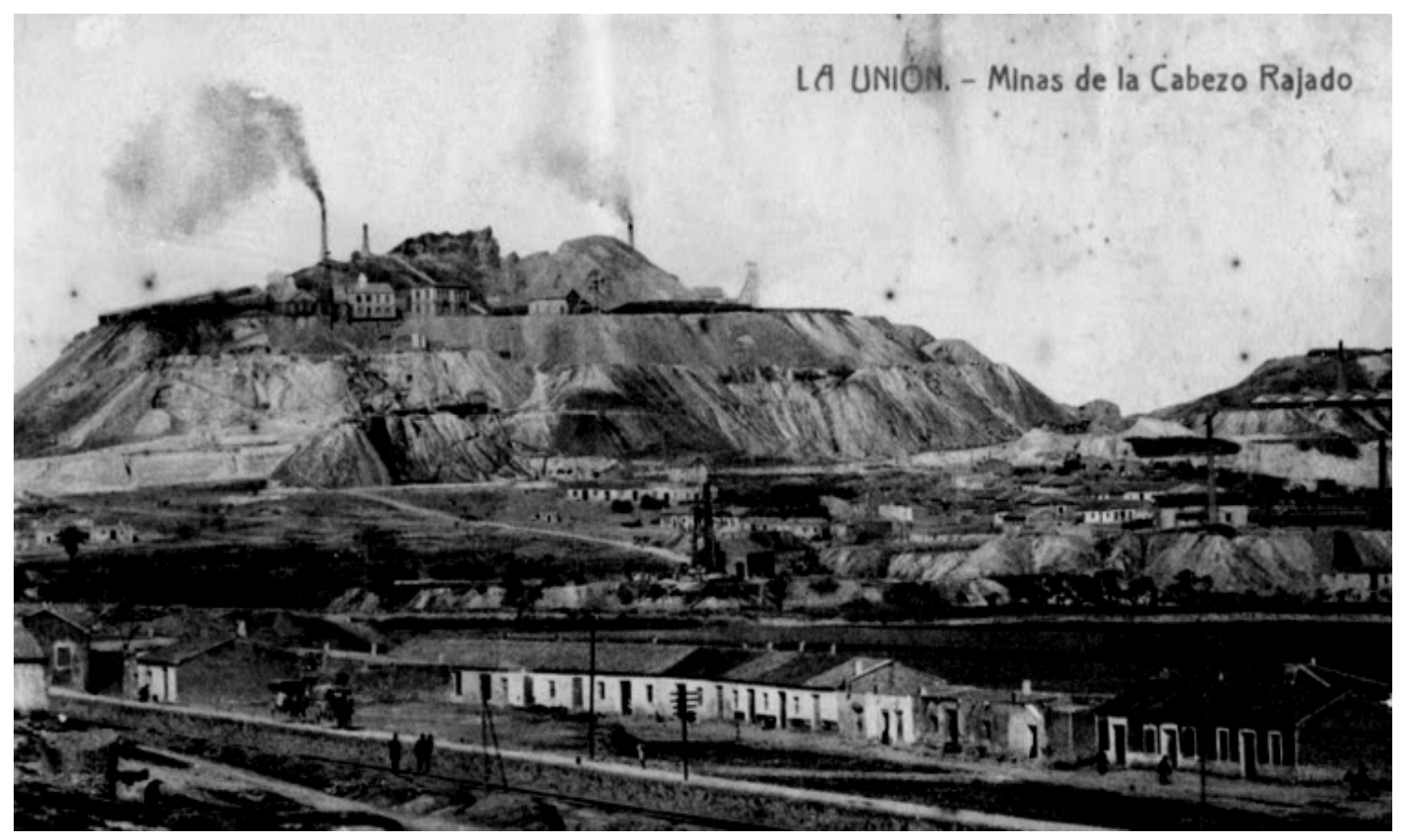

Figure 1: View of Cabezo Rajao in 1910 (source: Rogelio Mouzo Pagán. http://cronicasmineras.blogspot.com) 


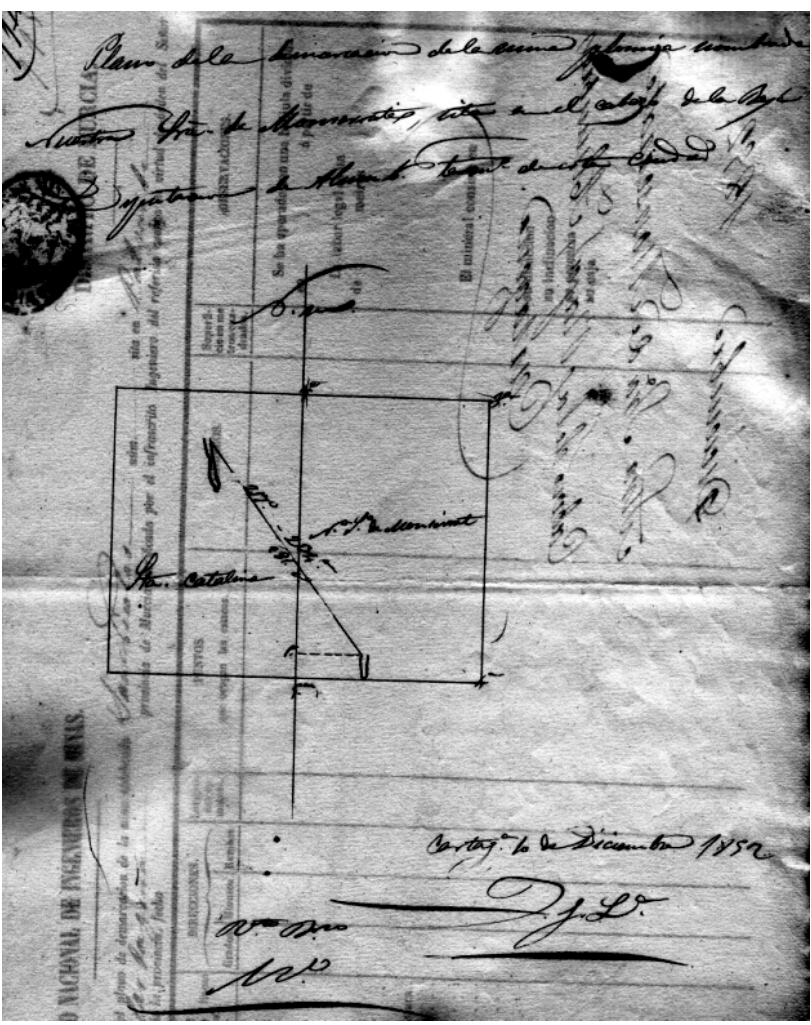

Figure 2: Original map of the claim (source: DirectorateGeneral for Industry, Energy and Mines of the Autonomous Region of Murcia)

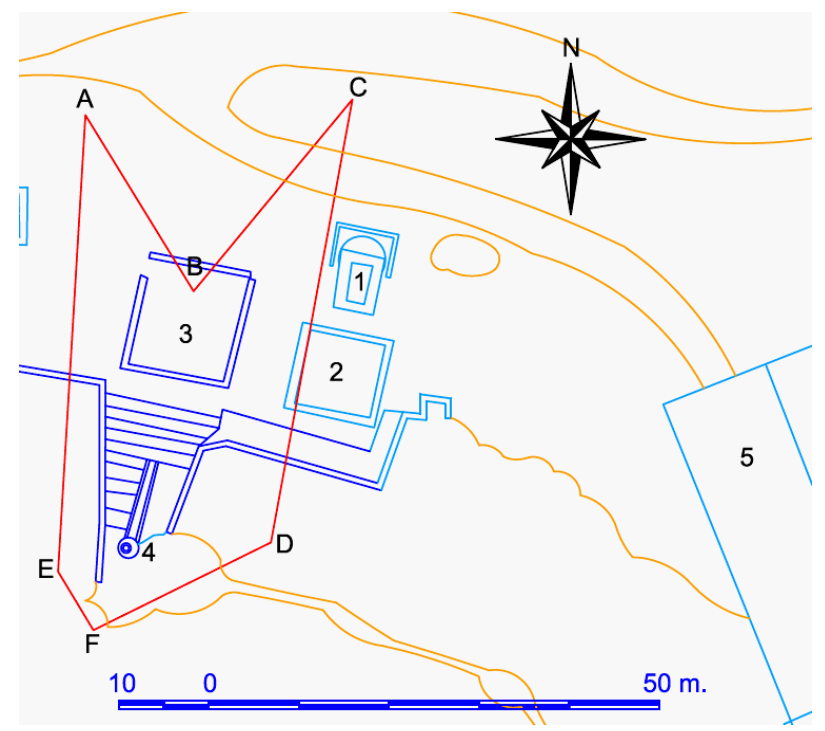

Figure 3: Sketch of premises and the traverse carried out (source: prepared by the authors)

\subsection{Data recording}

Field data were recorded in July 2016 by means of the MS50 multi-station. We used 6 stations linked by means of classical topography, whose location is shown in Figure 3. At each of these stations (located around the chimney), the point cloud corresponding to the studied area was collected with a density of $5 \times 5 \mathrm{~cm}$ at $\mathrm{A}, \mathrm{B}$ and $\mathrm{C}$ stations and $2 \times 2 \mathrm{~cm}$ at $\mathrm{D}, \mathrm{E}$ and $\mathrm{F}$ stations. A total of 800,000 points were recorded. At the same time, photographs were taken with a Canon EOS 1100D reflex camera and with two lenses (55-80 and 75-300).

Data collected have been processed by using the Leica Infinity computer software, with which the point cloud is exported from the multi-station to the PC and any existing noise is removed.

After having combined the point clouds collected in the field and after having removed any points outside the studied area, we found out that there was a hidden zone, with shadows, for which no information was available. In order to remedy this problem, we have used points from LIDAR models corresponding to 2009 , which are available at the publicly accessible web page http://iderm.imida.es/cartomur/.

Once that the relevant points have been selected and after having carried out the necessary transformations, we have combined the points from both clouds, the cloud collected in the field and that corresponding to LIDAR data, and we have obtained the cloud shown in Figure 4. The integration of different survey's methodologies can increase the efficacy of the representations (Balletti, Guerra, Scocca and Gottardi, 2015). Technologies such as laser scanning, LIDAR, high resolution photography, etc. can be used in documentation of historic sites (Wilson, Rawlinson, Mitchell, Pritchard and McGregor, 2011).

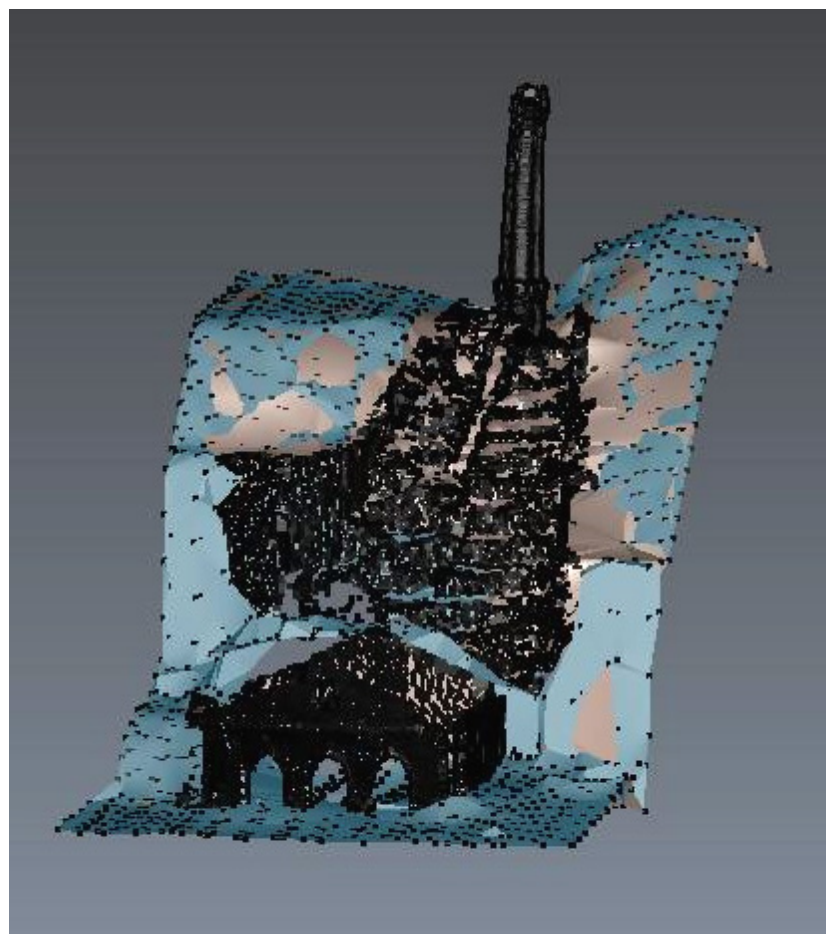

Figure 4: Combination of the own point cloud with that of LIDAR (source: prepared by the authors)

\subsection{D modelling and visualization}

After having prepared the final point cloud, the digital surface model has been created from a triangulated irregular network (TIN), by using the 3DReshaper software. Figure 5 shows a detail of the model and of the subsequent texturing process.

If we prepare a thematic map according to heights, we can observe the difference in heights of the model (Figure 6). 


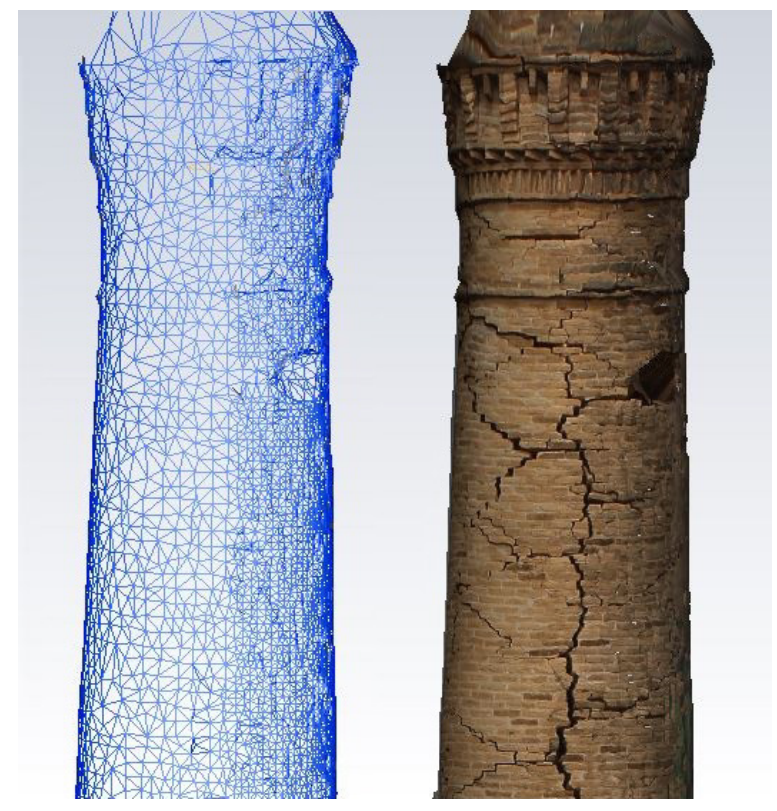

Figure 5: Detail of the TIN model and texturing (source: prepared by the authors)

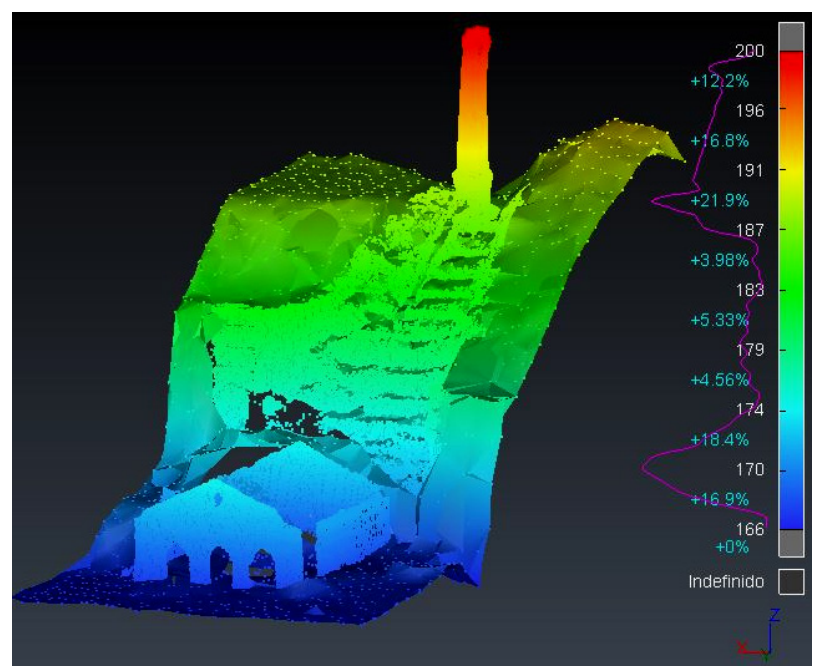

Figure 6: Thematic model according to heights (source: prepared by the authors)

According to the model, we have measured the planimetric displacement of the chimney. As shown in Figure 7, the distance between the base centre and the projection of the top centre is $48 \mathrm{~cm}$.

Once that the digital surface model has been debugged, we have textured it with the images taken by the multi-station and those captured by the photographic camera, after having properly calibrated it. The texturing process follows the idea that the applied technologies must not be noticeable, so that they are the instrument and not the purpose of the visualization (Carrozzino and Bergamasco, 2010). Figure 8 shows an area of the chimney in the textured model, which allows to notice and measure the existing cracks. Figure 9 shows a part of the textured model.

Based on the model, we have generated several 3D views for each element and for all of them as a whole.

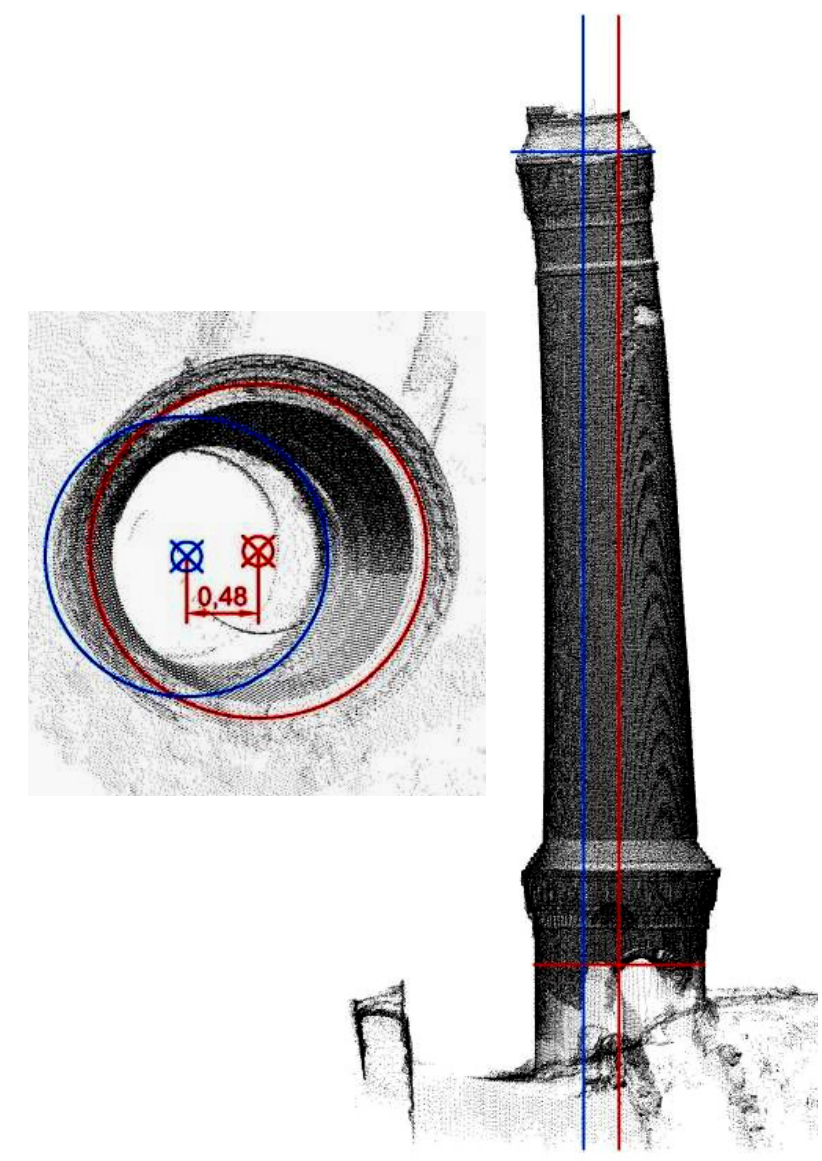

Figure 7: Ground plan and elevation, in which the displacement of the chimney can be noticed and measured (source: prepared by the authors)

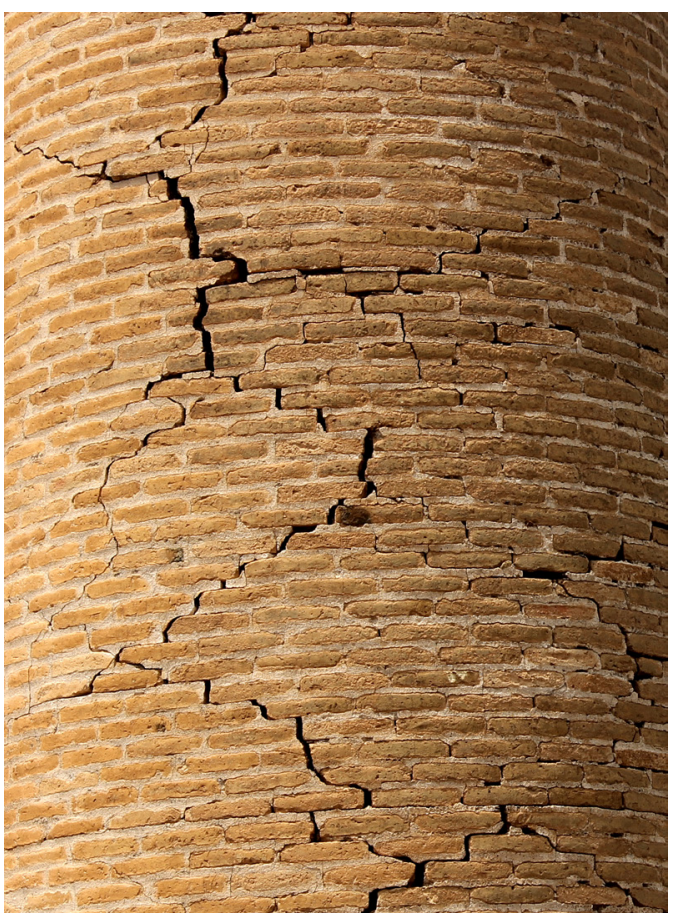

Figure 8: Detail of the textured model showing the cracks of the chimney (source: prepared by the authors) 


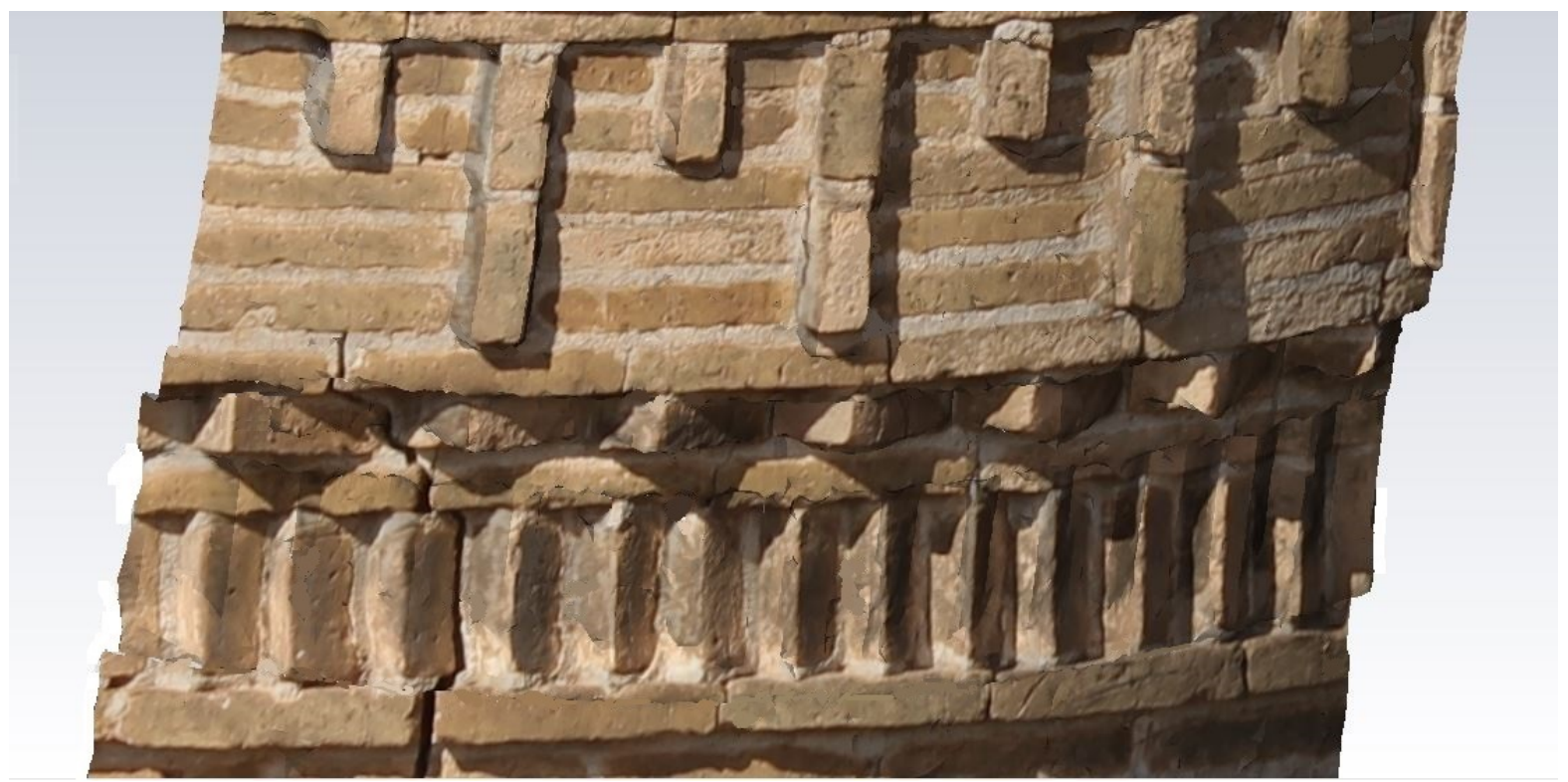

Figure 9: A part of the textured model (source: prepared by the authors)

\section{CONCLUSIONS}

Cabezo Rajao represents a genuine monument of industrial archaeology (Pérez de Perceval, Manteca and López Morell, 2010). Despite the fact that proposals have been made to recover and enhance its mining premises, none of the said proposals is currently being executed. The protection of these premises (not to mention their restoration) has become a problem that is common to other old mining areas (Koroso and Muñoz, 2009).

Our work has consisted in the survey (by means of a laserscanner) of a part of the Montserrat mine premises. Subsequently, we have prepared the 3D modelling of the set, by using photographs of the premises in order to generate a proper texture for the model.

The generated model may be used for several applications and disciplines. If the worst comes to the worst, it may be used to represent the state of the premises at a specific time and to supervise their deterioration from that time (Fassi, Rossi and Mandelli, 2015).

From the whole set, the chimney is the element that has a greater risk of collapse, as we have seen. We have measured the planimetric displacement of its top, which amounts to $48 \mathrm{~cm}$, and it has clearly visible cracks. That is why it would be a priority to urgently act before it is too late. The remaining elements have been plundered and they also have important damages of different types.

The documentation of this kind of sites is extremely important, but it does not replace the heritage physical preservation, for which it would be necessary to take urgent actions decided by the Administration. From this point of view, the tools that we have applied are very useful, given that they allow to place complete, accurate and realistic models at the disposal of experts, of those interested and of the general public. However, it is apposite to highlight the difficulties implied by the survey and the processing of data, which require a high degree of specialisation, and the need to have proper instruments.
One of the tasks yet to be carried out for this work is to assess the measurement quality of the created model, based on the NSSDA (National Standard for Spatial Data Accuracy) standards. Moreover, it is advisable to test the methodology with other premises, such as the head frames, in order to check its efficacy. Subsequently, we may consider carrying out a more or less systematic documentation task for the most emblematic -or most endangered- mining remains of Sierra Minera in order to generate an inventory of them.

\section{ACKNOWLEDGEMENTS}

To Leica-Geosystems for having lent us the 3DReshaper software for the carrying out of this study, in particular, to $\mathrm{Mr}$ Jesús Bonet. To the Honorary Collaborative Professor Mr José Ignacio Manteca Martínez, in his capacity of expert in Mining Heritage, for his comments on Cabezo Rajao.

\section{REFERENCES}

Balletti, C., Guerra, F., Scocca, V., Gottardi, C., 2015. 3D integrated methodologies for the documentation and the virtual reconstruction of an archaeological site. In: The International Archives of the Photogrammetry, Remote Sensing and Spatial Information Sciences, vol. XL-5/W4, pp. 215-222. DOI: 10.5194/isprsarchives-XL-5-W4-215-2015

Banos, I., Baños, P. (eds.), 2013. Portmán: de El Portus Magnus del Mediterráneo occidental a La Bahía Aterrada. Editum, Ediciones de la Universidad de Murcia

Cañizares, M.C., 2011. Protección y defensa del patrimonio minero en España. Scripta Nova, vol. XV, n. 361. Universidad de Barcelona. ISSN: 11389788

Carrozzino, M., Bergamasco. M., 2010. Beyond virtual museums: Experiencing immersive virtual reality in real museums. Journal of Cultural Heritage, 11(4), pp. 452-458 
Fassi, F., Rossi, C., Mandelli, A., 2015. Emergency survey of remote and endangered archaeological sites. In: The International Archives of the Photogrammetry, Remote Sensing and Spatial Information Sciences, vol. XL-5/W4, pp. 85-91. DOI: 10.5194/isprsarchives-XL-5-W4-85-2015

Koroso, I., Muñoz, O., 2009. Space throughout time, application of 3D virtual reconstruction and light projection techniques in the analysis and reconstruction of cultural heritage. ISPRS Archives, vol. XXXVIII-5/W1

Marcos, D., Martínez, J., Delgado, F.J., Finat, J., 2016. Explotaciones mineras en patrimonio industrial: un caso de uso de documentación y simulación. Proceedings of the $8^{\text {th }}$ International Congress on Archaeology, Computer Graphics, Cultural Heritage and Innovation, ARQUEOLÓGICA 2.0. Valencia (Spain). DOI:

http://dx.doi.org/10.4995/arqueologica8.2016.3565

Pérez de Perceval, M., Manteca, J.I., López Morell, M.A., 2010. Patrimonio minero de la Región de Murcia. Areas, 29. ISSN: 0211-6707

Wilson, L., Rawlinson, A., Mitchell, D.S., Pritchard, D.K., McGregor, H.C., 2011. 3D documentation of global historic sites: the 'Scottish Ten' project and its applications for cultural heritage. In: The International Archives of the Photogrammetry, Remote Sensing and Spatial Information Sciences, vol. XXXVIII-5/W16, pp. 39-44 